\title{
Editorial for the Special Issue on the 5th Automotive Technology Conference OTEKON2010, Uludag University, June 7-8, 2010, Bursa, Türkiye
}

\author{
Ferruh Öztürk
}

Published online: 11 April 2012

(C) Springer-Verlag London Limited 2012

This special issue of the International Journal of Advanced Manufacturing Technology (IJAMT) is devoted to the 5th Automotive Technology Conference OTEKON2010, which was held in Uludag University, Bursa, Turkey, June 7-8, 2010. The 5th Automotive Technology Conference OTEKON 2010 represented the continuation in a series of conferences, which was held every 2 years that aim to promote research and education to solve the current and future challenges in vehicle design, development and manufacturing. It was organized in Bursa from 7 to 8 June 2010 .

Over 100 papers were submitted to the conference, and 97 of them were invited to be presented at OTEKON 2010. All papers accepted to the conference were subject to review process prior to presentation at the conference, and finally, they were included in the proceedings. The authors of the selected papers were invited to submit an extended version of their papers to the special issue. The ten papers, which were presented at the conference, were selected for the possible publication in this special issue based on the review results of the conference papers, and the authors were invited to submit their papers. The selected papers were assessed by independent international and national assessors appointed by us. Then eight papers were accepted, and two of them were not accepted by the international and national review board.

As guest editor of this special issue of the International Journal of Advanced Manufacturing Technology, I would like to thank to the editor-in-chief of IJAMT, Prof.Dr. John Davies, for providing the opportunity to publish this special issue for the OTEKON2010 Conference. We are grateful in this regard to the reviewers who helped us during the reviewing process and selection of the papers. We would like to thank the authors for their contributions, and the reviewers and Springer production editor Claudia Kehl for their help in bringing this issue to its current form.

F. Öztürk $(\bowtie)$

Automotive Engineering Department, University of Uludag,

Gorukle,

Bursa 16059, Turkey

e-mail: ferruh@uludag.edu.tr 